\title{
The relationship of religious attitude with self-control and self-discrepancy in students
}

\author{
Masoud Nikfarjam ${ }^{1}$ Elham-Sadat Salehi ${ }^{*}$, Ali Ahmadi ${ }^{3}$ \\ ${ }^{1}$ Assistant Professor, Department of Psychiatry, Islamic Research committee, Shahrekord University of Medical Sciences, \\ Shahrekord, Iran \\ ${ }^{2}$ Student Research Committee, Shahrekord University of Medical Sciences, Shahrekord, Iran \\ ${ }^{3}$ Associate professor, Modeling in Health Research Center and Department of Epidemiology and Biostatistics, Shahrekord \\ University of Medical Sciences, Shahrekord, Iran
}

*Corresponding Author: Elham-Sadat Salehi; Student Research Committee, Shahrekord University of Medical Sciences, Shahrekord, Iran. Tel: elham_s91@yahoo.com; Email: +983833330061

\begin{abstract}
Background and aims: Spiritual attitude is one of the factors affecting mental health of students. The purpose of this study was to determine the relationship of religious attitudes with self-control and self-discrepancy (S-D) in students of Shahrekord University of Medical Sciences (SKUMS) in 2017.

Methods: In this cross-sectional study, 328 students of the SKUMS were studied. The participants completed Tangney Self-control Survey, Higgins Self-discrepancy Questionnaire, a religious attitude questionnaire, and a checklist of demographic information. For data analysis, in addition to descriptive statistics, independent t-test, Pearson correlation coefficient, and one-way ANOVA were used. Stata software was used to analyze the data.

Results: The mean values of religious attitude, self-control, and self-discrepancy were higher in women in comparison with men $(P<0.05)$. There was a significant difference between self-control religious beliefs, actual-self minus actual-self (S-D2), and self-discrepancy in terms of total monthly income of all family members $(P<0.05)$. Academic discipline was significantly associated with religious attitude, ideal-self minus actual-self (S-D1), S-D2, and S-D $(P<0.05)$, but self-control difference was not significant $(P=0.84)$. There was a linear relationship, significant correlation of religious attitude with the mean values of self-control, required self, actual-self, idea-self, self-discrepancy, and S-D1 and S-D2 $(P<0.05)$.

Conclusion: According to the results of this study, religious attitude was associated with self-control, self-discrepancy, and their dimensions. Keywords: Religious attitude; Self-control; Self-discrepancy; Student
\end{abstract}

Received: 6 February 2018, Accepted: 22 April 2019, ePublished: 20 June 2019

\section{Introduction}

Students of medical universities may develop mental health disorders by entering highly stressful learning environments such as hospitals and emergency departments and exposing to patients' diseases and mortality $(1,2)$. Therefore, it is essential to pay attention to various aspects of health in them. Spirituality is one of the important dimensions of human health. Spiritual health is one of the integral components of health, which was added to the definition of health at the Regional Conference of Eastern Mediterranean Directors (3). Therefore, according to the World Health Organization, Health is a dynamic state of complete, physical, mental, spiritual and social well-being, not just the absence of disease and disability (4). Spiritual attitude is one of the factors affecting mental health of students (5). This aspect addresses what the person feels about himself/herself, what he does, and why he does it (6). Spiritual well-being plays an indispensable role in maintaining and improving the health of individuals so that this aspect of spirituality is considered an integral and quality of life-related component of it and to promote health $(7-10)$.

On the other hand, psychologists believe that the most common and most significant disorders and behavioral problems are related to self (11). One of the issues that reflect a person's mental health is self-control whose decrease is a risk factor for the emergence of a wide range of individual and interpersonal problems (12). Self-control often involves resisting the most enjoyable motivations to achieve long-term goals (13). The ability to select goals and monitor progress towards them as well as the ability to regulate social behaviors comprises some part of self-control. Self-control capacity could increase worker performance and general health and it is a significant component of successful functioning (14).

Another aspect that can overwhelm the person's life is self-discrepancy (15). In his theory, Higgins talks of three types of self in individuals. According to Higgins, 
self consists of actual-self, idea-self, and required self. The actual-self represents the individual's sense of self in the present moment and what it should be. The actual-self refers to the wishes and hopes that a person imagines for himself. Ideal-self consists of the goals and ambition of an individual. Ultimately, required self includes the conscience and duties that a person feels responsible for and involves a sense of morality, commitment, and duty in individuals. The ideal and required self-comprises the standards for self-assessment of behavior and guidance for selfregulation in person (16). Understanding the gap between self-discrepancy, the individuals obtain information based on which they can evaluate themselves and by means of they can regulate themselves (17). Increasing self-rupture can lead to multiple psychological abnormalities (18); most notably, disappointment (19), shame (20), decreased self-esteem (21), and chronic psychological problems such as depression and fear of Community (22). Therefore, research in the field of self-concept and self-discrepancy provides a clear picture of the psychological problems of individuals. Self-concept and self-discrepancy can examine the individual's mental aspects in an in-depth manner and have a fundamental role in guiding people's behaviors (23). Students constitute a huge stratum of the active and efficient population of the country, and it is inevitable to pay attention to their health issues (24).

Accordingly, paying attention to their spiritual dimensions and psychological constructs for identifying and performing psychological and counseling interventions is urgent. Therefore, the present study was aimed to determine the relationship of religious attitudes with selfcontrol and self-discrepancy in Shahrekord University of Medical Sciences.

\section{Materials and Methods}

This cross-sectional study was conducted on students of the SKUMS in 2017. Stratified sampling was done on different faculties and the sample size was derived 324 according to the sample size formula. By taking into account dropouts, finally 328 people were included in the study. The inclusion criteria were willingness to participate in the study and fill out the questionnaires completely. Having mental disorders, having severe temporary stress (death of loved ones at the time of the study or the last few months), unavailability at the time of the implementation of the study, and lack of faith in religious principles were considered exclusion criteria. Students' information was collected through a Brief Self-Control Scale (BSCS), Higgins Self-Control Questionnaire, and a Religious Attitude Scale (RAS) and a checklist of demographic information. Demographic information was collected by a checklist containing questions such as age, gender, duration of study, economic status, family, and field of study. The RAS questionnaire was developed by Khodayarifard et al (25) to measure spiritual attitude. Then, the revision and adjustment of the short form (25 items) was done by Ebrahimi et al (26). The high psychometric quality and faster completion of the 40-question form are the characteristics of this questionnaire. The questionnaire includes components of the worldview and the quality of religious life, ethics and beliefs, worship and social behaviors, and inner spirituality. The Cronbach's alpha coefficient of the short version of the questionnaire was obtained 0.954 by test-retest (26).

Tangney's BSCS self-control questionnaire includes the ability to control one's self (leaving and breaking habits and working towards long-term goals). This questionnaire has 13 questions and aims to measure the amount of control of individuals on their own. The maximum and minimum scores for the questionnaire are 65 and 13, respectively. A higher score of the questionnaire is considered to indicate higher self-control. The self-control shortened scale, like its original version, has acceptable reliability and content validity (27). In the study of Tangney et al, the validity of this scale was confirmed by its correlation with subscales. Besides, its reliability on two study samples was obtained 0.83 and 0.85 using Cronbach's alpha test (12).

The last questionnaire examines self-discrepancy. This questionnaire was developed based on the Higgins selfdiscrepancy theory and a preliminary study. The selfdiscrepancy scale consisted of 27 5-point questions: 9 questions related to the actual-self, 9 for idea-self, and 9 for required self. The difference between the total actual scores and ideal and required self indicates actual-idea-selfdiscrepancy and actual-required self-discrepancy.

Negative numbers indicate lack of self-discrepancy, number zero indicates moderate self-discrepancy, and the positive numbers indicate the existence of self-discrepancy $(16,28)$. This scale has been localized by Samani and Sadeghzadeh and its reliability has been reported, by testretest method, to be 0.75 and 0.78 , respectively (29). Age and sex are confounding variables that were controlled by modeling and stratification of the variables.

Stata software was used to analyze the data. For data analysis, mean and standard deviation, frequency, percentages, independent $t$ test, Pearson coefficient test, and one-way ANOVA were used. The significance level was considered $<0.05$. In addition, the attitude variable was distinguished from knowledge by factor analysis.

\section{Results}

The participants in this study had mean age of $22.22 \pm$ 2.22 years. In addition, the mean academic duration was $37.75 \pm 19.79$ months, and the mean scores of religious attitude, self-control, actual-self, idea-self, and required self were $97.98 \pm 17.11,42.43 \pm 6.18,65.6 \pm 4.6,5.80 \pm 0.37$, and $35.82 \pm 5.61$, respectively. Of the 328 participants, $27.44 \%$ were males and $72.56 \%$ females. Significant differences were observed between boys and girls in light of religious attitude and the girls attained a significantly 
higher mean religious attitude than boys gender $(P<$ $0.001)$. Also, self-discrepancy $(P<0.001)$ and self-control $(P=0.048)$ was significantly different in light of gender so that girls showed a higher level of self-discrepancy and self-control (Table 1).

Students' academic disciplines caused a significant difference in religious attitude, S-D1, S-D2 and S-D among the students, but there was no significant difference in self-control $(P=0.84)$. The highest mean value of religious attitude was observed in the students of health and laboratory sciences, the highest mean value of S-D1 was observed in the students of laboratory sciences and radiology, and the highest mean value of S-D2 in the students of health, radiology and laboratory sciences, and the highest level of self-discrepancy was observed in the students of health, radiology, and laboratory sciences (Table 2).

There was a significant difference between religious attitude, self-control, S-D2, and self-discrepancy based on the total monthly income of all family members, but the total monthly income of all family members was not significantly associated with S-D1 among the students $(P$ $=0.07)$. The income of 2.2-5.2 million tomans attained the highest levels of religious attitudes, self-discrepancy, S-D1, and S-D2, and the income level of 2.5-5.5 million tomans attained the highest self-control (Table 3).

There was a linear relationship, significant correlation of religious attitude with mean value of self-control (0.29, $P<0.01)$. Also religious attitude was linearly related and

Table 1. Religious attitudes, self-control, and self-discrepancy in girls and boys

\begin{tabular}{lccc}
\hline \multirow{2}{*}{ Group } & Religious Attitude & Self-control & Self-discrepancy \\
\cline { 2 - 4 } & Mean \pm SD & Mean \pm SD & Mean \pm SD \\
\hline Male $(n=90)$ & $87.50 \pm 16.33$ & $41.41 \pm 6.87$ & $5.07 \pm 8.80$ \\
Female $(n=238)$ & $101.81 \pm 15.73$ & $42.68 \pm 5.88$ & $13.95 \pm 9.53$ \\
Total $(n=328)$ & $97.88 \pm 17.11$ & $42.33 \pm 6.18$ & $11.51 \pm 10.13$ \\
$P$ value & 0.001 & 0.048 & 0.01 \\
\hline
\end{tabular}

significantly correlated with mean value of required self, actual-self, idea-self, self-discrepancy, S-D1, and S-D2, but the relationship between religious attitude and age and education was not linear, although this relationship was not significant. Self-discrepancy and its subscales (S-D1 and S-D2), required self, and ideal-self were not significantly associated with age and education (Table 4).

\section{Discussion}

In the present study, there was a direct, significant correlation between religious attitude and mean values of self-control, required self, actual-self, idea-self, self-discrepancy, S-D1, and S-D2. Similarly, some studies have shown that there is a relationship between some aspects of self and spirituality and religious attitude. Laird et al found that self-control would lead to antisocial behavior and breach of law, and these behaviors were higher in adolescents who had lower self-control and lower spirituality scores (30). In another study, the results indicated that there was a correlation of self-control attributes and health related emotions with religion. In this study, which led to the creation of a model, it became clear how religion can influence mental health through self-control (31). Some studies have also shown that the ideal and required self in the two universities was different. The findings also indicate that religious differences in families are an effective factor in selfdiscrepancy level (32). This issue is likely to be influenced by the different cultures of societies, which subsequently influences their different norms, idea-self, and required self (33). The study by McCullough et al showed that religion controls human behavior indirectly through selfcontrol and self-regulation, which are related to each other (34). In a study that examined the relationship between religious attitudes and self-control among students, it was observed that religion plays a boosting role on self-control. There is also a significant, direct correlation of religious orientation and religious attitudes with self-control in students (35). In another study on girls aged before the

Table 2. Frequency distribution of participants according to the field of study and its relationship with the variables studied

\begin{tabular}{|c|c|c|c|c|c|c|}
\hline \multirow{2}{*}{ Level } & \multirow{2}{*}{ Number (\%) } & Religious Attitude & Self-control & S-D1 & S-D2 & S-D \\
\hline & & Mean \pm SD & Mean \pm SD & Mean \pm SD & Mean \pm SD & Mean \pm SD \\
\hline \multicolumn{7}{|l|}{ Field of study } \\
\hline Medicine & $124(37.80)$ & $94.66 \pm 19.99$ & $42.32 \pm 6.45$ & $4.16 \pm 5.48$ & $4.83 \pm 5.55$ & $8.99 \pm 10.69$ \\
\hline Nursing & $60(18.29)$ & $93.08 \pm 17.72$ & $41.93 \pm 5.20$ & $4.08 \pm 4.40$ & $4.98 \pm 5.18$ & $9.06 \pm 9.28$ \\
\hline Midwifery & $27(8.23)$ & $102.51 \pm 8.10$ & $43.33 \pm 5.69$ & $5.51 \pm 5.08$ & $7.29 \pm 4.35$ & $12.81 \pm 8.68$ \\
\hline Health & $48(14.63)$ & $106.16 \pm 11.08$ & $42.20 \pm 5.56$ & $7.54 \pm 4.04$ & $9.87 \pm 4.55$ & $17.41 \pm 8.03$ \\
\hline Radiology & $14(4.27)$ & $94.78 \pm 15.69$ & $40.28 \pm 9.45$ & $6.42 \pm 4.75$ & $8.71 \pm 7.02$ & $15.14 \pm 11.33$ \\
\hline Operating rooms & $25(7.62)$ & $99.00 \pm 15.27$ & $42.56 \pm 5.82$ & $5.84 \pm 3.67$ & $6.48 \pm 4.35$ & $12.32 \pm 7.40$ \\
\hline Laboratory sciences & $20(6.10)$ & $103.95 \pm 12.06$ & $43.60 \pm 7.20$ & $6.50 \pm 5.09$ & $7.85 \pm 6.36$ & $14.35 \pm 10.93$ \\
\hline Intelligence & $10(3.05)$ & $103.7 \pm 11.65$ & $43.60 \pm 6.60$ & $5.80 \pm 5.43$ & $7.20 \pm 4.73$ & $13.00 \pm 10.09$ \\
\hline Total & $328(100)$ & $97.88 \pm 17.11$ & $42.33 \pm 6.18$ & $5.17 \pm 5.01$ & $6.34 \pm 5.54$ & $11.51 \pm 10.13$ \\
\hline$P$ value & - & $<0.01$ & 0.84 & 0.002 & 0.001 & $<0.01$ \\
\hline
\end{tabular}

S-D1: Ideal-self minus actual-self, S-D2: Actual-self minus actual-self, S-D: Self-discrepancy (S-D1 + S-D2). 
Table 3. Distribution of the participants studied based on the total monthly income of all family members and its relationship with religious attitude, self-control, S-D1, S-D2 and self-discrepancy

\begin{tabular}{|c|c|c|c|c|c|c|}
\hline \multirow{2}{*}{$\begin{array}{l}\text { Variable Characteristic } \\
\text { (Toman) }\end{array}$} & \multirow{2}{*}{ Number $(\%)$} & \multirow{2}{*}{$\begin{array}{c}\text { Religious Attitude } \\
\text { Mean } \pm S D\end{array}$} & \multirow{2}{*}{$\begin{array}{c}\text { Self-control } \\
\text { Mean } \pm \text { SD }\end{array}$} & \multirow{2}{*}{$\begin{array}{c}\text { S-D1 } \\
\text { Mean } \pm \text { SD }\end{array}$} & \multirow{2}{*}{$\frac{\text { S-D2 }}{\text { Mean } \pm \text { SD }}$} & \multirow{2}{*}{$\frac{\text { S-D }}{\text { Mean } \pm \text { SD }}$} \\
\hline & & & & & & \\
\hline \multicolumn{7}{|c|}{ Total monthly income of all family members } \\
\hline$<6$ hundred thousand & $5(1.52)$ & $82.40 \pm 13.95$ & $36.20 \pm 3.56$ & $2.20 \pm 1.64$ & $-0.20 \pm 5.35$ & $2.00 \pm 6.67$ \\
\hline 6 hundred thousand -1 million & $20(6.10)$ & $97.80 \pm 14.17$ & $40.95 \pm 4.68$ & $4.40 \pm 4.19$ & $5.70 \pm 4.32$ & $10.10 \pm 8.09$ \\
\hline 1-1.5 million & $67(20.43)$ & $96.56 \pm 14.50$ & $42.14 \pm 4.96$ & $4.29 \pm 5.55$ & $5.43 \pm 6.02$ & $9.73 \pm 11.26$ \\
\hline 1.5-2 million & $110(33.54)$ & $99.99 \pm 18.44$ & $42.84 \pm 6.99$ & $5.35 \pm 5.03$ & $6.56 \pm 5.19$ & $11.91 \pm 9.90$ \\
\hline 2-2.5 million & $88(26.83)$ & $100.40 \pm 15.25$ & $42.52 \pm 6.08$ & $6.32 \pm 4.65$ & $7.73 \pm 5.52$ & $14.06 \pm 9.62$ \\
\hline 2.5-5 million & $24(7.32)$ & $93.12 \pm 15.14$ & $42.95 \pm 6.62$ & $4.91 \pm 4.13$ & $6.37 \pm 4.13$ & $11.29 \pm 7.41$ \\
\hline$>5$ million & $14(4.27)$ & $85.57 \pm 17.24$ & $41.14 \pm 6.59$ & $3.21 \pm 3.20$ & $3.50 \pm 3.03$ & $6.71 \pm 2.81$ \\
\hline Total & $328(100)$ & $97.88 \pm 17.11$ & $42.33 \pm 6.18$ & $5.17 \pm 5.01$ & $6.34 \pm 5.54$ & $11.51 \pm 10.13$ \\
\hline$P$ value & - & $<0.01$ & $<0.01$ & 0.07 & $\mathrm{P}<0.01$ & 0.013 \\
\hline
\end{tabular}

S-D1: Ideal-self minus actual-self, S-D2: Actual-self minus actual-self, S-D: Self-discrepancy (S-D1 + S-D2).

Table 4. Correlation coefficients and significance level of religious attitude with age, month, required, idea-self, actual-self, self-discrepancy, S-D1, and S-D2

\begin{tabular}{|c|c|c|c|c|c|c|c|c|c|}
\hline Variable & 1 & 2 & 3 & 4 & 5 & 6 & 7 & 8 & 9 \\
\hline 1. Religious attitude & 1.00 & $0.39(P<0.01)$ & $0.37(P<0.01)$ & $0.37(P<0.01)$ & $0.31(P<0.01)$ & $0.58(P<0.01)$ & $0.56(P<0.01)$ & $-0.05(0.26)$ & $-0.08(0.11)$ \\
\hline 2. S-D & & 1.00 & $0.95(P<0.01)$ & $0.96(P<0.01)$ & $-0.28(P<0.01)$ & $0.71(P<0.01)$ & $0.64(P<0.01)$ & $0.00(0.99)$ & $-0.06(0.26)$ \\
\hline 3. S-D1 & & & 1.00 & $0.84(P<0.01)$ & $-0.24(P<0.01)$ & $0.63(P<0.01)$ & $0.71(P<0.01)$ & $-0.01(0.81)$ & $-0.07(0.17)$ \\
\hline 4. S-D2 & & & & 1.00 & $-0.30(P<0.01)$ & $0.74(P<0.01)$ & $0.53(P<0.01)$ & $0.01(0.82)$ & $-0.04(0.42)$ \\
\hline 5. Actual-self & & & & & 1.00 & $0.41(P<0.01)$ & $0.50(P<0.01)$ & $0.03(0.53)$ & $0.50(0.32)$ \\
\hline 6. Idea-self & & & & & & 1.00 & $0.86(P<0.01)$ & $0.03(0.51)$ & $-0.003(0.94)$ \\
\hline 7. Ought self & & & & & & & 1.00 & $0.01(0.80)$ & $-0.02(0.61)$ \\
\hline 8. Age & & & & & & & & 1.00 & $0.76(P<0.01)$ \\
\hline 9. Education month & & & & & & & & & 1.00 \\
\hline
\end{tabular}

university, emotional maturity, actual-self, and required self were among the determinants of religious attitudes, but this relationship was not significant for actual-self (36).

In general, while religious beliefs and spiritual practices can be a powerful source of calmness, and hope and meaning in life, they have a complex connection with psychosocial disorders, and sometimes it is difficult to determine which one is the source or another (37). But it can be argued that spirituality and positive religious attitudes pave the way for achieving the desired mental health status (38). The feeling of belonging to a high source, hoping for God's help under stressful living conditions, and having spiritual support are the source by which religious people experience less damage dealing with difficulties and have higher control over their own behaviors by reinforcing various aspects of self and adjusting self-derived behaviors and thus enjoy higher levels of mental health.

\section{Conclusion}

According to the results of this study, religious attitude was associated with self-control, self-discrepancy, and its dimensions. Therefore, it is recommended to strengthen religious attitude through conducting educational, religious, and cultural programs to promote students' religious attitudes and their mental health.

Conflict of interests

None.

\section{Acknowledgements}

Hereby, we thank the research and technology deputy of Shahrekord University of medical sciences for funding this study (grant no. 2329).

\section{References}

1. Pedrelli P, Nyer M, Yeung A, Zulauf C, Wilens T. College students: mental health problems and treatment considerations. Acad Psychiatry. 2015;39(5):503-11. doi: 10.1007/s40596014-0205-9.

2. Batley NJ, Bakhti R, Chami A, Jabbour E, Bachir R, El Khuri $C$, et al. The effect of patient death on medical students in the emergency department. BMC Med Educ. 2017;17(1):110. doi: 10.1186/s12909-017-0945-9.

3. Nagase M. Does a Multi-Dimensional Concept of Health Include Spirituality? Analysis of Japan Health Science Council's Discussionson WHO's 'Definition of Health'(1998). Int J Appl Sociol. 2012;2(6):71-7. doi: 10.5923/j.ijas.20120206.03.

4. Dhar N, Chaturvedi S, Nandan D. Spiritual health scale 2011: defining and measuring 4 dimension of health. Indian J Community Med. 2011;36(4):275-82. doi: 10.4103/09700218.91329 .

5. Sadeghi MR, Bagherzadeh Ladari R, Haghshenas MR. A 
study of religious attitude and mental health in students of Mazandaran University of Medical Sciences. Journal of Mazandaran University of Medical Sciences. 2010;20(75):715. [Persian].

6. Torabi Chafjiri R, Navabi N, Shamsalinia A, Ghaffari F. The relationship between the spiritual attitude of the family caregivers of older patients with stroke and their burden. Clin Interv Aging. 2017;12:453-8. doi: 10.2147/cia.s121285.

7. Jafari N, Farajzadegan Z, Zamani A, Bahrami F, Emami $H$, Loghmani A, et al. Spiritual therapy to improve the spiritual well-being of Iranian women with breast cancer: a randomized controlled trial. Evid Based Complement Alternat Med. 2013;2013:353262. doi: 10.1155/2013/353262.

8. Dalmida SG, Holstad MM, Diiorio C, Laderman G. Spiritual well-being and health-related quality of life among AfricanAmerican women with HIV/AIDS. Appl Res Qual Life. 2011;6(2):139-57. doi: 10.1007/s11482-010-9122-6.

9. Jafari N, Farajzadegan Z, Loghmani A, Majlesi M, Jafari N. Spiritual well-being and quality of life of Iranian adults with type 2 diabetes. Evid Based Complement Alternat Med. 2014;2014:619028. doi: 10.1155/2014/619028.

10. Salsman JM, Yost KJ, West DW, Cella D. Spiritual well-being and health-related quality of life in colorectal cancer: a multisite examination of the role of personal meaning. Support Care Cancer. 2011;19(6):757-64. doi: 10.1007/s00520-0100871-4.

11. Sandler J, Person ES, Fonagy P. On narcissism: an introduction. Freud's" On Narcissism. London: Routledge; 2018.

12. Tangney JP, Baumeister RF, Boone AL. High self-control predicts good adjustment, less pathology, better grades, and interpersonal success. J Pers. 2004;72(2):271-324.

13. Duckworth A, Gross JJ. Self-control and grit: Related but separable determinants of success. Curr Dir Psychol Sci. 2014;23(5):319-25. doi: 10.1177/0963721414541462.

14. Pilcher JJ, Morris DM, Donnelly J, Feigl HB. Interactions between sleep habits and self-control. Front Hum Neurosci. 2015;9:284. doi: 10.3389/fnhum.2015.00284.

15. Lapp LK, Spaniol J. Aging and self-discrepancy: Evidence for adaptive change across the life span. Exp Aging Res. 2016;42(2):212-9. doi: 10.1080/0361073x.2016.1132900.

16. Higgins ET. Self-discrepancy: a theory relating self and affect. Psychol Rev. 1987;94(3):319-40.

17. Bak W. Self-standards and self-discrepancies. A structural model of self-knowledge. Curr Psychol. 2014;33:155-73. doi: 10.1007/s12144-013-9203-4.

18. Higgins ET. Continuities and discontinuities in self-regulatory and self-evaluative processes: a developmental theory relating self and affect. J Pers. 1989;57(2):407-44.

19. Stanley M, Burrow AL. The distance between selves: The influence of self-discrepancy on purpose in life. Self Identity. 2015;14(4):441-52. doi: 10.1080/15298868.2015.1008564.

20. Bessenoff GR, Snow D. Absorbing society's influence: Body image self-discrepancy and internalized shame. Sex Roles. 2006;54(9):727-31. doi: 10.1007/s11199-006-9038-7.

21. Moretti MM, Tory Higgins E. Relating self-discrepancy to self-esteem: The contribution of discrepancy beyond actualself ratings. J Exp Soc Psychol. 1990;26(2):108-23. doi: 10.1016/0022-1031(90)90071-S.

22. Strauman TJ. Self-discrepancies in clinical depression and social phobia: cognitive structures that underlie emotional disorders? J Abnorm Psychol. 1989;98(1):14-22.
23. Thomas CM. The influence of self-concept on adherence to recommended health regimens in adults with heart failure. J Cardiovasc Nurs. 2007;22(5):405-16. doi: 10.1097/01. JCN.0000287037.85067.3d.

24. Madah Karani Z, Elahi T, Fathi-Ashtiyani A. Explanation of psychological well-being in students based on spirituality and resiliency. Int J Behav Sci. 2014;7(4):355-61. [Persian].

25. Khodayarifard M, Shahabi R, Akbari-Zardkhaneh S. Religiosity, self-control and tendency to substance abuse among university students. Soc Welfare. 2009;9 (34):115-30.

26. Ebrahimi A, Neshatdoost H, Kalantari M, Molavi H, Asadollahi G. Factor structure, reliability and validity of Religious Attitude Scale. Journal of Fundamentals of Mental Health. 2008;10(38):107-16. [Persian].

27. de Ridder DT, Lensvelt-Mulders G, Finkenauer C, Stok FM, Baumeister RF. Taking stock of self-control: a metaanalysis of how trait self-control relates to a wide range of behaviors. Pers Soc Psychol Rev. 2012;16(1):76-99. doi: $10.1177 / 1088868311418749$.

28. Higgins ET. Continuities and discontinuities in self-regulatory and self-evaluative processes: a developmental theory relating self and affect. J Pers. 1989;57(2):407-44.

29. Samani S, Sadeghzadeh M. [Self-discrepancy in adolescents based on family process and content model]. Stud Edu Psychol. 2007;8(2):111-24.

30. Laird RD, Marks LD, Marrero MD. Religiosity, self-control, and antisocial behavior: Religiosity as a promotive and protective factor. J Appl Dev Psychol. 2011;32(2):78-85. doi: 10.1016/j. appdev.2010.12.003.

31. Briki W, Aloui A, Bragazzi NL, Chaouachi A, Patrick T, Chamari K. Trait self-control, identified-introjected religiosity and health-related-feelings in healthy muslims: a structural equation model analysis. PLoS One. 2015;10(5):e0126193. doi: 10.1371/journal.pone.0126193.

32. Kameli S, Ghooshchy SG. Studying the self- discrepancy of students in different species of family in process model and family content. Procedia Soc Behav Sci. 2011;30:1113-7. doi: 10.1016/j.sbspro.2011.10.217.

33. Radhakrishnan $P$, Chan DKS. Cultural Differences in the Relation between Self-discrepancy and Life Satisfaction. Int J Psychol. 1997;32(6):387-98. doi: 10.1080/002075997400638.

34. McCullough ME, Willoughby BL. Religion, self-regulation, and self-control: Associations, explanations, and implications. Psychol Bull. 2009;135(1):69-93. doi: 10.1037/a0014213.

35. Hosseinkhanzadeh AA, Yeganeh T, Mojallal M. The relationship of the religious orientations and attitudes with self-control among students. Procedia Soc Behav Sci. 2013;84:759-62. doi: 10.1016/j.sbspro.2013.06.641.

36. Mohammadyari E, Khodabakhshi-Koolaee A. Investigating the effects of emotional maturity and self--discrepancy on the religious attitude of pre-college adolescent girls in Tehran. Journal of Research on Religion \& Health. 2017;3(2):31-42. [Persian].

37. Koenig HG. Research on religion, spirituality, and mental health: a review. Can J Psychiatry. 2009;54(5):283-91. doi: 10.1177/070674370905400502.

38. Dadkhah Tehrani T, Habibian N, Ahmadi R. The Relationship between Religious Attitudes and Psychological Well-being of Nurses Working in Health Centers in Qom University of Medical Sciences in 2014. Health, Spirituality and Medical Ethics. 2015;2(4):15-21. [Persian]. 